\title{
Factors influencing circulating MicroRNA level in the studies of hepatocellular carcinoma biomarker
}

\author{
Y. WANG ${ }^{1,2, \neq}$, Z. LIANG ${ }^{3, *}$, Y. GAO ${ }^{4, *}$, D. ZHAI ${ }^{4}$, Q. RAO ${ }^{1}$, W. SHI ${ }^{4}$, B. YANG ${ }^{4}$, L. JING ${ }^{4}$, H. GUO ${ }^{4}$, T. LIU ${ }^{4}$, J. LIU' ${ }^{1}$, Z. DU $U^{4,5}$ \\ ${ }^{1}$ Third Central Clinical College of Tianjin Medical University, Tianjin 300170, China; ${ }^{2}$ Department of Blood Transfusion, Tianjin Medical \\ University General Hospital, Tianjin 300052, China; ${ }^{3}$ Department of General Surgery (Blood Vessel), Cangzhou People's Hospital, Cangzhou \\ 061000, China; ${ }^{4}$ Key Laboratory of Artificial Cell, Institute for Hepatobiliary Disease, Tianjin Third Central Hospital, Tianjin 300170, China; \\ ${ }^{5}$ Department of Hepatobiliary Surgery, Tianjin Third Central Hospital, Tianjin 300170, China
}

*Correspondence: gaoyt816@163.com

${ }^{\ddagger}$ Contributed equally to this work.

Received March 13, 2015 / Accepted May 6, 2015

Factors influencing circulating miRNA as a diagnostic marker of hepatocellular carcinoma (HCC) are still unknown. We used two kits to extract total RNA of 90 paired serum and plasma samples of volunteers in different statuses including healthy, hepatitis, cirrhosis and HCC. U6, miR-183 and cel-miR-39 expression levels were detected by qRT-PCR. Calculate was the relative expression level of miR-183 and recovery of cel-miR-39 with $2^{-\Delta \Delta C T}$ method and standard curve method, respectively.

MiRNeasy Serum/Plasma Kit was superior to miRcute miRNA Isolation Kit in the quality of the total RNA and the expression levels of U6 and miR-183, with recovery of external reference cel-miR-39 of the former in serum and plasma was the latter's 3.95-fold and 3.15-fold, respectively. The recovery of cel-miR-39 was significantly higher in serum than that in plasma in all groups except the HCC. But the trend of U6 expression of four groups in serum was different from that in plasma. There were significant differences in absorbance in $260 \mathrm{~nm}$, the ratio of absorbance in $260 \mathrm{~nm}$ and $280 \mathrm{~nm}(260 / 280)$, the ratio of absorbance $260 \mathrm{~nm}$ and 230nm (260/230), the ct value of U6 and the recovery of cel-miR-39 among groups in serum or plasma. Sensitivity and specificity of miR-183 as a diagnostic marker of HCC were $57.9 \%$ and $76.2 \%$ in serum, and $78.9 \%$ and $81.0 \%$ in plasma, respectively.

Caution should be taken when comparing miRNA data generated from different extraction kits, sample types or disease statuses in the study of miRNA as a diagnostic marker of HCC.

Key words: disease status, extraction, plasma, qRT-PCR, serum

Hepatocellular carcinoma (HCC) has exhibited an increase in morbidity and mortality. Most patients are usually diagnosed at advanced stages and miss the best time for therapy, resulting in a poor prognosis. Hence, it is still important to search for a sensitive and specific biomarker to screen earlystage HCC. MicroRNAs (miRNAs) are a type of endogenous small non-coding RNAs and function either as oncogenes or as tumor-suppressor genes during cancer development [1]. Studies indicated that miRNAs were derived from tissues and organs and were resistant to RNAse activity, as well as to extreme $\mathrm{pH}$ and temperature, which made them notably stable in serum and plasma samples [2-6]. Moreover, a variety of methods for the detection of miRNAs has been developed. Among them, quantitative real-time reverse-transcription polymerase chain reaction (qRT-PCR) is a quantitative method with high sensitivity and specificity [7]. Currently, many researchers have found that circulating miRNAs express differentially in patients with HCC and may serve as new biomarkers of HCC [8-14]. However, these studies have shown variable results. Owing to the lack of a comprehensive understanding of circulating miRNAs, it is difficult to determine the factors that may affect their quantification. Some investigators use to estimate miRNAs mainly in the blood of healthy subjects predicted that circulating miRNA levels may be affected by various factors like different extraction kits [15-19], sample types [20-27] or disease status $[4,9,10]$. So far there few studies have specifically compared these factors in liver disease.

Our previous study analyzed the differential expression of 88 miRNAs in 11 pairs of HCC patients and matched NT tissues and we found that miR-183 was most significantly 
upregulated in HCC patient (7.127-fold) [28]. In another experiment, we found that miR-183 was useful in differentiating HCC from benign liver diseases or normal controls [29]. In addition, U6 [30-32] and cel-miR-39 [5, 33-35] have been used as internal control and external reference in many studies, respectively. Thus, we selected up-regulated miR-183, internal control U6 and the external reference cel-miR-39 as the target miRNAs and detected their expression level in plasma or serum by qRT-PCR. Our aims were to explore the impacts of different extraction methods, different types of samples and various disease statuses on the circulating miRNA expression level in the patients with liver disease and provide methodological basis for further studying circulating miRNA as a diagnostic marker of HCC.

\section{Patients and methods}

Patients and samples. We collected paired serum and plasma samples of 21 healthy individuals, 19 hepatitis patients, 12 patients with cirrhosis and 38 HCC patients at the Tianjin Third Central Hospital (Tianjin, China) between May 2013 and November 2013. The written informed consent was obtained from each participant and this study was approved by the Ethics Committee of the hospital.

RNA isolation. In this experiment we used miRcute miRNA Isolation Kit (cat. no. DP501, Tiangen, China) and miRNeasy Serum/Plasma Kit (cat. no. 217184, Qiagen, Germany) to extract total RNA from 71 and 19 paired serum and plasma samples, respectively. Take $200 \mu \mathrm{L}$ serum/plasma and add 3.5 $\mu \mathrm{L}$ miRNeasy Serum/Plasma Spike-In Control (mimic of Caenorhabditis elegans miR-39, cel-miR-39) and $1 \mu \mathrm{L}$ carrier RNA (bacterial ribosomal RNA), then operate following the manufacturer's instructions. The concentration and purity of the total RNA were measured by BioPhotometer (Eppendorf, Germany).

\section{Reverse transcription of miRNA.}

The reverse transcription of U6 and miR-183. CDNA was synthesized by TaqMan ${ }^{\circ}$ MicroRNA Reverse Transcription Kit (cat. no. 4366569, Applied Biosystems, USA). The synthesis reaction consisted of $2 \mu \mathrm{L}$ total RNA, $3 \mu \mathrm{L}$ specific primer, 0.1 $\mu \mathrm{L}$ dNTP $\operatorname{mix}(100 \mathrm{mM}), 3 \mu \mathrm{L} 5 \times \mathrm{RT}$ buffer, $1.0 \mu \mathrm{L}_{\text {MultiScribe }} \mathrm{mt}^{\mathrm{mt}}$ RT enzyme $(50 \mathrm{U} / \mu \mathrm{l}), 1.8 \mu \mathrm{L} \mathrm{MgCl}_{2}$, and $4.1 \mu \mathrm{L}$ nuclease free water. The synthesis reaction conditions were $16^{\circ} \mathrm{C}$ for $30 \mathrm{~min}$, $42^{\circ} \mathrm{C}$ for $30 \mathrm{~min}$ and $85^{\circ} \mathrm{C}$ for $5 \mathrm{~min}$.

The reverse transcription of cel-miR-39. The reverse transcription of cel-miR-39 standard curve. CDNA was synthesized with miScript II RT Kit (cat. no. 218161, Qiagen, Germany). The $20 \mu \mathrm{L}$ reverse transcription reaction contained $2.2 \mu \mathrm{l} 1 \times 10^{8}$ copies/ $\mu$ l working solution of cel-miR-39, $2 \mu$ lany total RNA sample, $4 \mu \mathrm{l} 5 \times$ miScript HiSpec Buffer, $2 \mu \mathrm{l} 10 \times$ miScript Nucleics Mix, $7.8 \mu \mathrm{l}$ RNase-free water, and $2 \mu \mathrm{lmiScript}$ Reverse Transcriptase Mix. The reaction was carried out at $37^{\circ} \mathrm{C}$ for $60 \mathrm{~min}$ and $95^{\circ} \mathrm{C}$ for $5 \mathrm{~min}$. After the reaction, the product was stored on ice and diluted with $200 \mu \mathrm{L}$ RNase-free water. Use the diluted reverse transcription reaction to prepare cDNA serial dilutions, $5 \times 10^{5}$ copies $/ \mu \mathrm{l}, 5 \times 10^{4}$ copies $/ \mu \mathrm{l}, 5 \times 10^{3}$ copies $/ \mu \mathrm{l}$, and $5 \times 10^{2}$ copies $/ \mu$ l.

The reverse transcription of external reference cel-miR-39. Total RNA samples were reverse-transcribed to cDNA with miScript II RT Kit. The $20 \mu \mathrm{L}$ reverse transcription reaction contained $1.5 \mu \mathrm{L}$ total RNA, $4 \mu \mathrm{L} 5 \times$ miScript HiSpec Buffer, $2 \mu \mathrm{L} 10 \times$ miScript Nucleics Mix, $2 \mu \mathrm{L}$ miScript Reverse Transcriptase Mix, and $10.5 \mu \mathrm{L}$ nuclease free water. The reaction was carried out described above and the product was diluted with $200 \mu \mathrm{L}$ RNase-free water.

\section{QRT-PCR of miRNA.}

The qRT-PCR of miR-183 and U6. The qRT-PCR of U6 and miR-183 was performed by TaqMan Universal PCR Master Mix (Applied Biosystems, USA) on the ABI ViiA ${ }^{\mathrm{TM}} 7$ real-time PCR system (Applied Biosystems, USA). The amplification reaction system consisted of $1 \mu \mathrm{L}$ cDNA, $5 \mu \mathrm{L} 2 \times \mathrm{TaqMan}^{\infty}$ Universal PCR Master Mix, 0.5 $\mu \mathrm{L} 20 \times \mathrm{TaqMan}^{\circ}$ Assay (containing specific probe of has-miR-183 or U6, the sequence of which were UAU GGCACUGGUAGAAUUCACU and GTGCTCGCTTCGGCAGCACATATAC

T AAAA TTGGAACGATA CAGAGA A G A T T A G C A T G G C C C C T G C G C A A G G A TGACACGCAAATTCGTGAAGCGTTCCATATTTT, respectively) and nuclease- free water added to reach a final volume of $10 \mu \mathrm{L}$. Reaction was carried out at $95^{\circ} \mathrm{C}$ for $10 \mathrm{~min}$, followed by 40 cycles at $95^{\circ} \mathrm{C}$ for $15 \mathrm{~s}$ and $60^{\circ} \mathrm{C}$ for $60 \mathrm{~s}$. The expression of miR-183 was calculated using $2^{-\triangle \Delta C T}$ method [36].

The qRT-PCR of cel-miR-39. The qRT-PCR of cel-miR-39 standard curve. The qRT-PCR of cel-miR-39 serial dilutions was carried out with miScript SYBR Green PCR Kit (cat. no. 218075, QIAGEN, Germany) in the following reaction mixtures: $5 \mu \mathrm{L} 2 \times$ QuantiTect SYBR Green PCR Master Mix, $1 \mu \mathrm{L}$ $10 \times$ miScript Universal Primer, $1 \mu \mathrm{L} 10 \times$ Ce miR-39 $1 \mathrm{miScript}$ Primer Assay (sequence: UCACCGGGUGUAAAUCAGCUUG), $1 \mu \mathrm{L}$ RNase-free water, $2 \mu \mathrm{L}$ template cDNA. Reaction conditions were $95{ }^{\circ} \mathrm{C}$ for $15 \mathrm{~min}$, followed by 40 cycles at $94^{\circ} \mathrm{C}$ for $15 \mathrm{~s}, 55^{\circ} \mathrm{C}$ for $30 \mathrm{~s}$ and $70^{\circ} \mathrm{C}$ for $34 \mathrm{~s}$. Each sample was run repeatedly. Generate a standard curve by plotting the log copy number cel-miR-39 used in each PCR against the mean cycle threshold $(\mathrm{Ct})$ value.

The qRT-PCR of external reference cel-miR-39. The qRT-PCR of cel-miR-39 of each sample was carried out with miScript SYBR Green PCR Kit in the following reaction mixtures: $5 \mu \mathrm{L} 2 \times$ QuantiTect SYBR Green PCR Master Mix, $1 \mu \mathrm{L} 10 \times$ miScript Universal Primer, $1 \mu \mathrm{L} 10 \times$ Ce miR-39 1 miScript Primer Assay, $2 \mu \mathrm{L}$ RNase-free water, $1 \mu \mathrm{L}$ template cDNA. Reaction conditions were described above. Extract Ct values and compare with the cel-miR-39 standard curve to determine recovery of cel-miR-39.

Statistical analysis. SPSS 19.0 software was used for the statistical analysis. Normally distributed continuous variables were presented as the mean \pm standard deviation (Mean \pm SD) and the difference between two sets of paired data was obtained by paired Student's t-test. Non-normally distributed continuous variables were expressed as median (range, 25th and 75th 
percentiles) and Mann-Whitney U test was used to compare the difference between the two groups. Analysis of variance or Kruskal-Wallis $\mathrm{H}$ test were used in comparison among the groups. $P<0.05$ was considered statistically significant.

\section{Results}

Comparison between miRcute miRNA Isolation Kit and miRNeasy Serum/Plasma Kit. Total RNAs were extracted from 19 paired serum and plasma samples of patients with HCC by miRcute miRNA Isolation Kit and miRNeasy Serum/ Plasma Kit, respectively. The concentration and purity of the total RNA were measured by Bio Photometer. The miRNA extraction effect of miRNeasy Serum/Plasma Kit (absorbance in $260 \mathrm{~nm}$ (A260), ratio of $260 \mathrm{~nm}$ and $280 \mathrm{~nm}(260 / 280)$ and ratio of $260 \mathrm{~nm}$ and $230 \mathrm{~nm}(260 / 230)$ ) were better than miRcute miRNA Isolation Kit's, and the differences were statistically significant $(P<0.05$, Table1). Expression levels of U6, miR-183 and external reference cel-miR-39 of each extracted sample were detected by qRT-PCR and our results showed that ct value of each miRNA extracted by miRNeasy Serum/Plasma Kit was lower than that by miRcute miRNA Isolation Kit and the cel-miR-39 recovery of the former kit in serum and plasma is the latter kit's 3.95-fold and 3.15-fold, respectively. All the differences above were statistically significant $(P<0.05$, Table 1$)$. In addition, all the ct values of U6, miR-183 and cel-miR-39 were less than 35 suggesting that miRNA extracted by the two kits could be detected. Although miRNeasy Serum/Plasma Kit was superior to miRcute miRNA Isolation Kit, both of them could be used to extract miRNA from serum and plasma samples. Since miRcute miRNA Isolation Kit was more affordable and more accessible, total RNA was extracted using miRcute miRNA Isolation Kit in the following studies.

Comparison of miRNA extraction effect between serum and plasma. Total RNAs of paired serum and plasma samples obtained from 21 healthy volunteers, 19 patients with hepatitis, 12 patients with cirrhosis and 19 patients with HCC were isolated using miRcute miRNA Isolation Kit. U6 expression level was detected by qRT-PCR. U6 level was significantly higher in serum than in plasma in the healthy control group and the cirrhosis group $(P<0.001, P=$ $0.011)$. For patients with hepatitis, serum U6 level increased comparing with plasma U6 level, but the difference was not statistically significant $(P=0.312)$. In contrast, U6 level in serum was higher than that in plasma for HCC patients $(P=$ 0.022). We then detected the expression level of cel-miR-39 of these samples, calculated the recovery of cel-miR-39, and found the recovery of cel-miR-39 was significantly higher in serum than in plasma for the healthy control group, hepatitis group and cirrhosis group $(P=0.012, P=0.002, P=0.015)$. Although there was no significant difference in HCC group $(P=0.058)$, the recovery of cel-miR-39 had an increasing trend in serum compared to plasma. The results mentioned above were summarized in Table 2.

Table1. Comparison of miRNA extraction effect between two kits

\begin{tabular}{|c|c|c|c|}
\hline Index & miRcute miRNA Isolation Kit $(\bar{x} \pm S)$ & miRNeasy Serum/Plasma Kit $(\bar{x} \pm S)$ & $P$ \\
\hline A260 of serum & $0.042 \pm 0.011$ & $0.083 \pm 0.028$ & $<0.001$ \\
\hline A260 of plasma & $0.045 \pm 0.010$ & $0.061 \pm 0.019$ & 0.010 \\
\hline A260/280 of serum & $0.994 \pm 0.120$ & $1.880 \pm 0.081$ & $<0.001$ \\
\hline A260/280 of plasma & $1.036 \pm 0.148$ & $1.773 \pm 0.132$ & $<0.001$ \\
\hline A260/230 of serum & $0.252 \pm 0.070$ & $0.737 \pm 0.739$ & 0.013 \\
\hline A260/230 of plasma & $0.272 \pm 0.090$ & $1.173 \pm 0.818$ & $<0.001$ \\
\hline Ct value of U6 in serum & $27.750 \pm 2.435$ & $23.723 \pm 3.495$ & $<0.001$ \\
\hline Ct value of U6 in plasma & $29.278 \pm 3.014$ & $27.292 \pm 1.596$ & 0.005 \\
\hline Ct value of miR-183 in serum & $33.614 \pm 1.737$ & $31.334 \pm 1.759$ & 0.001 \\
\hline Ct value of miR-183 in plasma & $33.081 \pm 1.669$ & $29.832 \pm 2.058$ & 0.002 \\
\hline Recovery of cel-miR-39 of serum & $0.077 \pm 0.010$ & $0.304 \pm 0.025$ & $<0.001$ \\
\hline Recovery of cel-miR-39of plasma & $0.040 \pm 0.053$ & $0.126 \pm 0.083$ & 0.002 \\
\hline
\end{tabular}

Table 2. Comparison of miRNA extraction effect between serum and plasma

\begin{tabular}{|c|c|c|c|c|c|c|}
\hline \multirow[t]{2}{*}{ Group } & \multicolumn{3}{|c|}{ U6 } & \multicolumn{3}{|c|}{ Recovery of cel-miR-39 } \\
\hline & $\begin{array}{c}\text { Serum } \\
(\bar{x} \pm S)\end{array}$ & $\begin{array}{c}\text { Plasma } \\
(\bar{x} \pm S)\end{array}$ & $\mathrm{P}$ & $\begin{array}{c}\text { Serum } \\
(\bar{x} \pm S)\end{array}$ & $\begin{array}{c}\text { Plasma } \\
(\bar{x} \pm S)\end{array}$ & $\mathrm{P}$ \\
\hline Healthy control group & $31.452 \pm 2.681$ & $26.690 \pm 2.282$ & $<0.001$ & $0.003 \pm 0.002$ & $0.002 \pm 0.003$ & 0.012 \\
\hline Hepatitis group & $28.201 \pm 1.199$ & $27.815 \pm 2.088$ & 0.312 & $0.150 \pm 0.091$ & $0.076 \pm 0.031$ & 0.002 \\
\hline Cirrhosis group & $29.828 \pm 2.379$ & $27.253 \pm 2.358$ & 0.011 & $0.096 \pm 0.056$ & $0.047 \pm 0.026$ & 0.015 \\
\hline HCC group & $27.750 \pm 2.435$ & $29.278 \pm 3.015$ & 0.022 & $0.077 \pm 0.043$ & $0.040 \pm 0.054$ & 0.058 \\
\hline
\end{tabular}



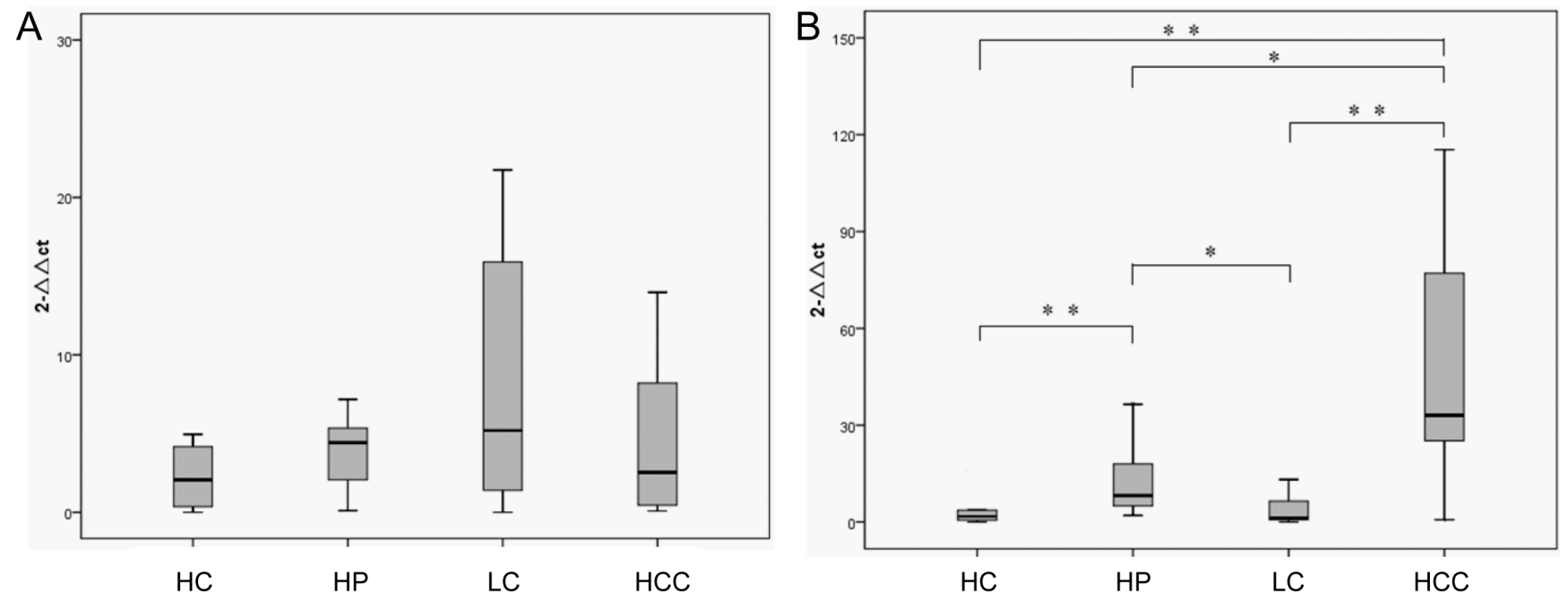

Figure 1. Relative expression level of miR-183 in different groups.

A demonstrates the relative expression levels of serum miR-183 in different groups; $B$ demonstrates the relative expression levels of plasma miR-183 in different groups. HC represents the healthy control group; HP represents the hepatitis group; LC represents the liver cirrhosis group; HCC represents the hepatocellular carcinoma group. ${ }^{\star}$ represents $P<0.05$; ${ }^{\star *}$ represents $P<0.001$.

Comparison of miRNA extraction effect among groups. We analyzed total RNA purity, the level of internal control U6, and the recovery of external reference cel-miR-39 of paired serum and plasma samples mentioned above, which were obtained from healthy control, patients with hepatitis, cirrhosis and HCC and extracted by miRcute miRNA Isolation Kit. We found the absorbance in $260 \mathrm{~nm}$ (A260), the ratio of absorbance in $260 \mathrm{~nm}$ and $280 \mathrm{~nm}(260 / 280)$, the ratio of absorbance in $260 \mathrm{~nm}$ and $230 \mathrm{~nm}(260 / 230)$, the ct value of U6 and the recovery of cel-miR-39 were all significantly different among groups (all the $\mathrm{P}$ values were less than 0.05 , Table 3 ).

Comparison of miR-183 diagnosis value for HCC in serum and plasma. We detected the expression level of miR-183 of above total RNAs extracted by miRcute miRNA Isolation Kit, then calculated the relative expression level of miR-183

Table 3. Comparison of miRNA extraction effect among groups

\begin{tabular}{lcc}
\hline Index & F/Chi-Square & $P$ \\
\hline A260 of serum & $4.806^{\mathrm{c}}$ & 0.004 \\
$\mathrm{~A} 260^{\mathrm{a}}$ of plasma & $6.019^{\mathrm{c}}$ & 0.001 \\
$\mathrm{~A} 260 / 280^{\mathrm{b}}$ of serum & $52.580^{\mathrm{d}}$ & $<0.001$ \\
$\mathrm{~A} 260 / 280^{\mathrm{a}}$ of plasma & $37.395^{\mathrm{c}}$ & $<0.001$ \\
$\mathrm{~A} 260 / 230^{\mathrm{b}}$ of serum & $47.942^{\mathrm{d}}$ & $<0.001$ \\
$\mathrm{~A} 260 / 230^{\mathrm{a}}$ of plasma & $17.661^{\mathrm{c}}$ & $<0.001$ \\
$\mathrm{U} 6^{\mathrm{b}}$ in serum & $23.219^{\mathrm{d}}$ & $<0.001$ \\
U6 $6^{\mathrm{a}}$ in plasma & $3.889^{\mathrm{c}}$ & 0.013 \\
Recovery of cel-miR-39 of serum & $47.165^{\mathrm{d}}$ & $<0.001$ \\
Recovery of cel-miR-39 of plasma & $40.419^{\mathrm{d}}$ & $<0.001$ \\
\hline
\end{tabular}

a, Data have homogeneity of variance; $b$, Data have heterogeneity of variance; c, Value of $F$; d, Value of Chi-Square.
(Fig. 1), and analyzed the ability of serum/plasma miR-183 to distinguish HCC group from healthy control group, hepatitis group and cirrhosis group by receiver operating characteristics (ROC) curve (Fig. 2). The relative expression level of serum miR-183 was $2.060(0.271 \sim 4.429)$ in healthy control group, 4.427 (1.580 5.372) in hepatitis group, 5.203 (0.751 18.472)

\section{ROC Curve}

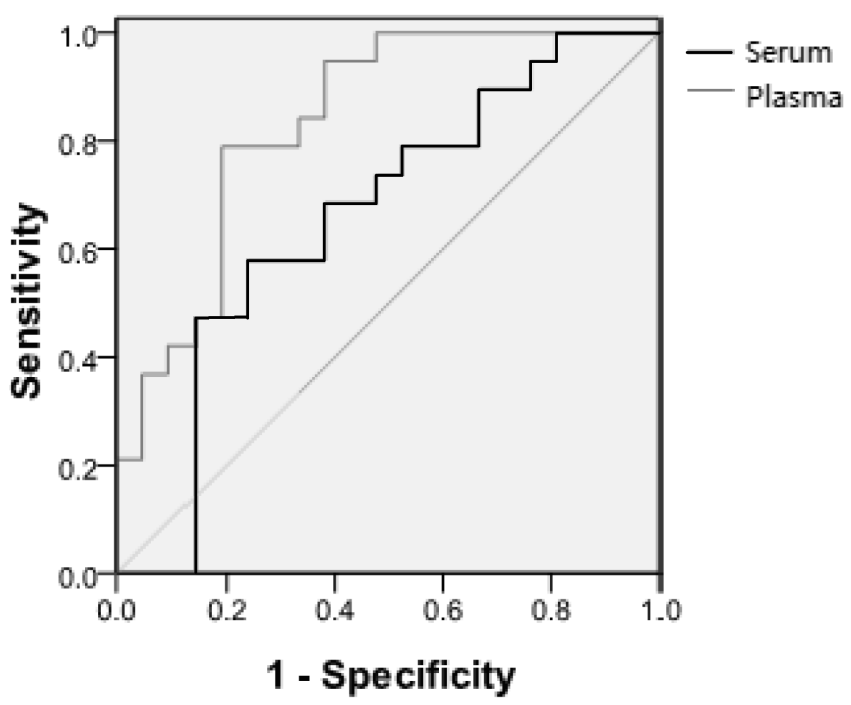

Figure 2. Receiver operating characteristics (ROC) curve of circulating miR-183 to differentiate HCC patients from benign liver diseases or healthy controls. Serum represents the ROC curve of serum miR-183; Plasma represents the ROC curve of plasma miR-183 
in cirrhosis group, and 2.534 (0.332 10.885) in HCC group (Fig. 1A). The relative expression level of plasma miR-183 was $1.738(0.455 \sim 3.722)$ in healthy control group, 8.202 (4.138 20.591) in hepatitis group, $1.241(0.577 \sim 8.073)$ in cirrhosis group, and 33.081 (24.606 86.759) in HCC group (Fig. 1B). For serum miR-183, the AUC was 0.662 with $95 \%$ CI: $0.488-0.835$. Cutoff value was 4.272 , where the sensitivity and specificity were $57.9 \%$ and $76.2 \%$, respectively (Fig. 2). For plasma miR-183, the area under the curve (AUC) was 0.837 with $95 \%$ confidence interval (CI): 0.713-0.961. Cutoff value was 3.955 , where sensitivity and specificity were $78.9 \%$ and $81.0 \%$, respectively (Fig. 2).

\section{Discussion}

Currently, several studies have demonstrated that circulating miRNAs are differentially expressed in patients with liver disease and are potential biomarkers useful in HCC diagnosis. Even though circulating miRNA holds promise, there still are numerous challenges that can affect accurate analysis of circulating miRNAs in clinical practice. Factors that may affect the measurement of circulating miRNA have yet to be fully clarified.

Here we compared the extraction efficience of two frequently utilized commercially available miRNA isolation kits. All the ct values of U6 extracted by the two kits were less than 35 , suggesting that both of the two kits could be used to extract miRNA. Nevertheless, miRNeasy Serum/Plasma Kit was superior to miRcute miRNA Isolation Kit in the quality of the total RNA and the expression level of internal control U6, with the recovery of external reference cel-miR-39 of the former in serum and plasma was the latter's 3.95-fold and 3.15-fold, respectively. Our results indicated that although different kits were reported to be suitable, the yield and quality of miRNA could vary widely between kits, which may be a major factor accounting variability in reported miRNA profiles. Similarly, many studies [16-19] have validated our results. For example, Page $\mathrm{K}$ et al. [15] compared miRvana microRNA Isolation kit, miRNeasy Serum/Plasma kit and QIAamp ${ }^{\circ}$ Circulating Nucleic Acids kit for miRNA islation and found there were marked differences in recovery of spike-in miRNA between the three kits. The result of Melissa Ah et al. [17] also demonstrated an apparent difference in recovery of the spiked-in cel-miR-39 between the miRCURY Biofluids kit and miRNeasy Serum/ Plasma kit. Therefore, as suggested previously, [37] levels of circulating miRNA extracted using different methods should not be compared directly, and we should carefully select the isolation method and stick to it during the whole course of a given study.

There have been some studies comparing miRNA expression between serum and plasma. Mithchell et al. [5] confirmed that abundance of miR-15b, miR-16, miR-19b and miR-24 in serum and plasma collected from the same individual were highly correlated, indicating that both serum and plasma samples would be suitable for investigations of miRNAs as blood-based biomarkers. However, Wang et al. [20] found that serum samples had higher RNA concentration than the corresponding plasma samples from 12 healthy individuals, but their further studies suggested that RNA released during the coagulation process may change the true level of circulating miRNA and plasma may be a better choice for studying circulating miRNA. In contrast, some other researchers thought that serum was better for circulating miRNA detection, since plasma contained cellular material that may introduce contaminating cellular miRNAs from apoptotic or lysed cells (e.g. RBCs, platelets), [19, 24-27] as well as anti-coagulants such as heparin that could inhibit downstream reaction [2123]. Since previous studies on the type of specimen remains controversial, we compared the expression level of U6 and the recovery of cel-miR-39 in serum and corresponding plasma in the healthy group, hepatitis group, cirrhosis group and HCC group. The recovery of cel-miR-39 was significantly higher in serum than in plasma in all groups except the HCC group, suggesting that miRNA extraction effect of serum specimens was really different from plasma specimens and serum specimens was more suitable for miRNA extraction.

In the present study we also compared extraction efficiency of circulating miRNA among four groups with different status, and found that the recovery of cel-miR-39, miRNA content (A260 and ct value of U6), quality of extraction (260/280 and 260/230) were significantly different between each two groups in serum or plasma samples, suggesting that the disease status may affect miRNA extraction efficiency. Previous studies have indicated disease status may influence circulating miRNA levels. For example, Chen et al [4] found that the expression profiles of serum miRNAs in patients with non-small cell lung carcinoma, colorectal cancer, and type 2 diabetes had a significantly different serum miRNA profile compared to healthy volunteers. Li et al. [9] compared miRNA expression profiles in HBV serum with that in control serum and found serum miRNA differentially expressed in HBV serum. Zhou et al. [10] reported that plasma miRNA panel can differentiate HCC from healthy, chronic hepatitis B, and cirrhosis, respectively. Our results are not only consistent with these previous studies but also may be one reason why different diseases have different miRNA expression profiles.

For the same type of extraction kit, considering comprehensively the impact of specimen type and disease status on the miRNA detection in liver disease, we analyzed the value of serum and plasma miR-183 in the diagnosis of HCC by ROC curve and found the specificity and sensitivity of plasma miR-183 was superior to serum miR-183 in HCC diagnosis. Although our experiment showed that serum samples were more suitable for miRNA extraction, it is a better choice to select plasma samples in the study of miRNA as a diagnostic marker of HCC.

In summary, caution must be taken when comparing miRNA data generated from different extraction kits, sample types or disease status. We recommend choosing plasma samples in the study of miRNA as a diagnostic marker of HCC. 
Acknowledgments: This study was supported by grants from the Key Research Projects of the Tianjin Healthy Bureau (11KG112).

\section{References}

[1] GIORDANO S, COLUMBANO A. „MicroRNAs: new tools for diagnosis, prognosis and therapy in HCC?” Hepatology 2013; 57: 840-847. http://dx.doi.org/10.1002/hep.26095

[2] HENEGHAN HM, MILLER N, LOWERY AJ, SWEENEY KJ, NEWELL J, et al. Circulating microRNAs as novel minimally invasive biomarkers for breast cancer. Ann Surg 2010; 251: 499-505. http://dx.doi.org/10.1097/SLA.0b013e3181cc939f

[3] CHIN LJ, SLACK FJ. A truth serum for cancer--microRNAs have major potential as cancer biomarkers. Cell Res 2008; 18: 983-984. http://dx.doi.org/10.1038/cr.2008.290

[4] CHEN X, BA Y, MA L, CAI X, YIN Y, et al. Characterization of microRNAs in serum: a novel class of biomarkers for diagnosis of cancer and other diseases. Cell Res 2008; 18: 997-1006. http://dx.doi.org/10.1038/cr.2008.282

[5] MITCHELL PS, PARKIN RK, KROH EM, FRITZ BR, WYMAN SK, et al. Circulating microRNAs as stable blood-based markers for cancer detection. Proc Natl Acad Sci USA 2008; 105: 10513-8. http://dx.doi.org/10.1073/ pnas. 0804549105

[6] GILAD S, MEIRI E, YOGEV Y, BENJAMIN S, LEBANONY $\mathrm{D}$, et al. Serum microRNAs are promising novel biomarkers. PLoS One 2008; 3: e3148. http://dx.doi.org/10.1371/journal. pone. 0003148

[7] CHEN Y, GELFOND JA, MCMANUS LM, SHIREMAN PK. Reproducibility of quantitative RT-PCR array in miRNA expression profiling and comparison with microarray analysis. BMC Genomics 2009; 10: 407. http://dx.doi.org/10.1186/14712164-10-407

[8] TOMIMARU Y, EGUCHI H, NAGANO H, WADA H, KOBAYASHI S, et al. Circulating microRNA-21 as a novel biomarker for hepatocellular carcinoma. J Hepatol 2012; 56: 167-75. http://dx.doi.org/10.1016/j.jhep.2011.04.026

[9] LI LM, HU ZB, ZHOU ZX, CHEN X, LIU FY, et al. Serum microRNA profiles serve as novel biomarkers for HBV infection and diagnosis of HBV-positive hepatocarcinoma. Cancer Res 2010; 70: 9798-807. http://dx.doi.org/10.1158/0008-5472. CAN-10-1001

[10] ZHOU J, YU L, GAO X, HU J, WANG J, et al. Plasma microRNA panel to diagnose hepatitis B virus-related hepatocellular carcinoma. J Clin Oncol 2011; 29: 4781-8. http://dx.doi. org/10.1200/JCO.2011.38.2697

[11] XU J, WU C, CHE X, WANG L, YU D, et al. Circulating microRNAs, miR-21, miR-122, and miR-223, in patients with hepatocellular carcinoma or chronic hepatitis. Mol Carcinog 2011; 50: 136-42. http://dx.doi.org/10.1002/mc.20712

[12] XU J, ZHU X, WU L, YANG R, YANG Z, et al. MicroRNA122 suppresses cell proliferation and induces cell apoptosis in hepatocellular carcinoma by directly targeting $\mathrm{Wnt} / \beta$ catenin pathway. Liver Int 2012; 32: 752-60. http://dx.doi. org/10.1111/j.1478-3231.2011.02750.x

[13] QI P, CHENG SQ, WANG H, LI N, CHEN YF, et al. Serum microRNAs as biomarkers for hepatocellular carcinoma in
Chinese patients with chronic hepatitis B virus infection. PLoS One 2011; 6: e28486. http://dx.doi.org/10.1371/journal. pone.0028486

[14] LI J, WANG Y, YU W, CHEN J, LUO J. Expression of serum miR-221 in human hepatocellular carcinoma and its prognostic significance. Biochem Biophys. Res Commun 2011; 406: 70-3. http://dx.doi.org/10.1016/j.bbrc.2011.01.111

[15] PAGE K, GUTTERY DS, ZAHRA N, PRiMrose L, ELSHAW SR, et al. Influence of plasma processing on recovery and analysis of circulating nucleic acids. PLoS One 2013; 8: e77963. http://dx.doi.org/10.1371/journal.pone.0077963

[16] ELDH M, LOTVALL J, MALMHÄLL C, EKSTROM K. Importance of RNA isolation methods for analysis of exosomal RNA: evaluation of different methods. Mol Immunol 2012; 50: 278-86. http://dx.doi.org/10.1016/j.molimm.2012.02.001

[17] MCALEXANDER MA, PHILLIPS MJ, WITWER KW. Comparison of Methods for miRNA Extraction from Plasma and Quantitative Recovery of RNA from Cerebrospinal Fluid. Front Genet 2013; 4: 83. http://dx.doi.org/10.3389/ fgene. 2013.00083

[18] ACH RA, WANG H, CURRY B. Measuring microRNAs: comparisons of microarray and quantitative PCR measurements, and of different total RNA prep methods. BMC Biotechnol 2008; 8: 69. http://dx.doi.org/10.1186/1472-6750-8-69

[19] MCDONALD JS, MILOSEVIC D, REDDI HV, GREBE SK, ALGECIRAS-SCHIMNICH A. Analysis of circulating microRNA: preanalytical and analytical challenges. Clin Chem 2011; 57: 833-40. http://dx.doi.org/10.1373/ clinchem.2010.157198

[20] WANG K, YUAN Y, CHO JH, MCCLARTY S, BAXTER D, et al. Comparing the MicroRNA spectrum between serum and plasma. PLoS One. 2012; 7(7): e41561. http://dx.doi. org/10.1371/journal.pone.0041561

[21] JOHNSON ML, NAVANUKRAW C, GRAZUL-BILSKA AT, REYNOLDS LP, REDMER DA. Heparinase treatment of RNA before quantitative real-time RT-PCR. Biotechniques 2003; 35: 1140-2, 1144.

[22] BAI X, FISCHER S, KESHAVJEE S, LIU M. Heparin interference with reverse transcriptase polymerase chain reaction of RNA extracted from lungs after ischemia-reperfusion. Transpl Int 2000; 13: 146-50. http://dx.doi.org/10.1111/j.14322277.2000.tb01055.x

[23] GARCIA ME, BLANCO JL, CABALLERO J, GARGALLOVIOLA D. Anticoagulants interfere with PCR used to diagnose invasive aspergillosis. J Clin Microbiol 2002; 40: 1567-8. http://dx.doi.org/10.1128/JCM.40.4.1567$\underline{1568.2002}$

[24] HASTINGS ML, PALMA J, DUELLI DM. Sensitive PCRbased quantitation of cell-free circulating microRNAs. Methods 2012; 58: 144-50. http://dx.doi.org/10.1016/j. ymeth.2012.07.026

[25] KIM DJ, LINNSTAEDT S, PALMA J, PARK JC, NTRIVALAS E, et al. Plasma components affect accuracy of circulating cancer-related microRNA quantitation. J Mol Diagn 2012; 14: 71-80. http://dx.doi.org/10.1016/j.jmoldx.2011.09.002

[26] COSTA MC, LEITAO AL, ENGUITA FJ. MicroRNA Profiling in Plasma or Serum Using Quantitative RT-PCR. Methods 
Mol Biol 2014; 1182: 121-9. http://dx.doi.org/10.1007/978$\underline{1-4939-1062-5 \quad 11}$

[27] PRITCHARD CC, KROH E, WOOD B, ARROYO JD, DOUGHERTY KJ, et al. Blood Cell Origin of Circulating MicroRNAs: A Cautionary Note for Cancer Biomarker Studies. Cancer Prev Res (Phila) 2012; 5: 492-7. http://dx.doi. org/10.1158/1940-6207.CAPR-11-0370

[28] LI J, SHI W, GAO Y, YANG B, JING X, et al. Analysis of MicroRNA ExpressionProfiles in Human Hepatitis B Virus-Related Hepatocellular Carcinoma. Clin Lab 2013; 59: 1009-15.

[29] LIANG Z, GAO Y, SHI W, ZHAI D, LI S, et al. Expression and Significance of MicroRNA-183 in Hepatocellular Carcinoma. ScientificWorldJournal 2013; 2013: 381874. http://dx.doi. org/10.1155/2013/381874

[30] JIANG J, LEE EJ, GUSEV Y, SCHMITTGEN TD. Real-time expression profiling of microRNA precursors in human cancer cell lines. Nucleic Acids Res 2005; 33: 5394-403. http://dx.doi. org/10.1093/nar/gki863

[31] AMBS S, PRUEITT RL, YI M, HUDSON RS, HOWE TM, et al. Genomic profiling of microRNA and messenger RNA reveals deregulated microRNA expression in prostate cancer. Cancer Res 2008; 68: 6162-70. http://dx.doi. org/10.1158/0008-5472.CAN-08-0144
[32] SCHAEFER A, JUNG M, MILLER K, LEIN M, KRISTIANSEN $\mathrm{G}$, et al. Suitable reference genes for relative quantification of miRNA expression in prostate cancer. Exp Mol Med 2010; 42: 749-58. http://dx.doi.org/10.3858/emm.2010.42.11.076

[33] FARINA NH, WOOD ME, PERRAPATO SD, FRANCKLYN CS, STEIN GS, et al. Standardizing Analysis of Circulating MicroRNA: Clinical and Biological Relevance. J Cell Biochem 2014; 115: 805-11. http://dx.doi.org/10.1002/jcb.24745

[34] MACLELLAN SA, MACAULAY C, LAM S, GARNIS C. Preprofiling factors influencing serum microRNA levels. BMC Clin Pathol 2014; 14: 27. http://dx.doi.org/10.1186/1472-6890 $\underline{-14-27}$

[35] MCALEXANDER MA, PHILliPS MJ, WITWER KW. Comparison of methods for miRNA extraction from plasma and quantitative recovery of RNA from cerebrospinal fluid. Front Genet 2013; 4: 83. http://dx.doi.org/10.3389/ fgene.2013.00083

[36] LIVAK KJ, SCHMITTGEN TD. Analysis of Relative Gene Expression Data Using RealTime Quantitative PCR and the 2- $\Delta \Delta$ CT Method. Methods 2001; 25: 402-8. http://dx.doi. org/10.1006/meth.2001.1262

[37] BAKER M. MicroRNA profiling: separating signal from noise. Nat Methods 2010; 7: 687-692. http://dx.doi.org/10.1038/ nmeth0910-687 